\title{
Como o jovem de São Paulo ouve rádio?
}

\section{How do young people listen to radio in São Paulo?}

Daniel Gambaro ${ }^{1}$

1 Doutorando e mestre (2011) em Meios e Processos Audiovisuais pela Escola de Comunicação e Artes da USP. Graduado em Rádio e Televisão pela Universidade Anhembi Morumbi (2005). Rádio, televisão e suas relações com as mídias digitais compõem os principais objetos de pesquisa. E-mail: dgambaro@usp.br. 


\section{Resumo}

O objetivo deste artigo é demonstrar como as emissoras de rádio de São Paulo, voltadas para o público jovem e jovem adulto (até 30 anos), estão requalificando suas operações e grades de programação, como forma de atender a uma nova demanda da audiência. A introdução de redes sociais na dinâmica dos programas adicionou novas possibilidades de interação entre as emissoras e uma audiência altamente conectada. Além disso, as estações passaram a oferecer mais conteúdo em seus websites: fotos, vídeos, playlists de músicas pré-configuradas, notícias segmentadas em assuntos etc. Agora, os programas no dial também estão mudando: podemos notar uma presença maior do apresentador radiofônico durante a reprodução musical, inclusive com mais interação com a audiência. Assim, esta pesquisa apresenta como as cinco principais emissoras paulistanas de audiência jovem modificaram suas estruturas de conteúdo.

\section{Palavras-chave}

Rádio, público jovem, internet, comunicador radiofônico. 


\section{Abstract}

This paper analyses how São Paulo radio stations targeting the young audience (up to 30 years old) are reconfiguring their services and schedules to serve a new audience demand. The introduction of social networks in the dynamics of the shows has added new possibilities of interaction between a highly connected audience and the broadcaster. Besides that, the stations started offering more content in their webpages: photo, video, predetermined musical playlists, segmented news, etc. Now, the programmes on dial are also changing: we can now notice more presence of the radio presenter during the musical programming, including more live interaction to the listeners. This paper demonstrates how the five main radio stations segmented to young audience in São Paulo have made major changes to their content production structure.

\section{Keywords}

Radio, youngsters, internet, radio presenter. 
A multiplicação da oferta de conteúdos em diferentes medias, consequência da proliferação de tecnologias de comunicação que emergiram do entorno digital em que vivemos, provoca uma discussão de fundo de extrema relevância: como se comporta a audiência? Se a relevância dessa questão é premente nos meios de comunicação digitais, ela se torna ainda mais central quando concernidos os meios considerados "tradicionais", como o rádio e a televisão. No cenário brasileiro - em que está contido o recorte desta análise - , o caso do rádio é bastante significativo. Dados de mercado mostram, desde 2004, queda na penetração entre todos os públicos, o que parece indicar uma migração da audiência para outros veículos especialmente aqueles baseados em internet, uma vez que esses dados coincidem com o crescimento do acesso a conexões em banda-larga². Entre 2004 e 2013, a penetração total do veículo entre todos os públicos caiu de $90 \%$ para $71 \%$.

O comportamento dos públicos adolescente e jovem adulto - e a resposta das emissoras de rádio ao movimento da audiência - é um fator importante nessa conta. Em se tratando de um veículo massivo como rádio, a ligação com a vida cotidiana e o costume de consumo são elementos centrais na manutenção da audiência enquanto esta envelhece. Conforme os dados consolidados de audiência mais recentes, a faixa etária de 15 a 29 anos corresponde a 31\% do público total do rádio (GRUPO DE MÍDIA SP, 2015). Em 2004, essa mesma faixa etária correspondia a $36 \%$ do total, o que possibilita afirmar que a faixa que mais perdeu audiência é justamente a do adolescente e do jovem adulto, reproduzindo no Brasil uma tendência que se observa em outros países, como anota Rudin sobre o Reino Unido (2013, p. 66).

Algumas emissoras de rádio segmentadas, especialmente na audiência mencionada, vêm implementando mudanças em suas grades de programação, com vistas muitas vezes a atender novas demandas e promover a fidelização de um público que parece escapar entre os dedos. Isso não quer dizer, no entanto, que as estratégias adotadas sejam realmente eficazes ou mesmo inovadoras: parece haver muito mais continuidades do que experimentações em direção a algo inovador. Ainda assim, mesmo que as estratégias sejam tímidas, vale a pena observar como as diferentes empresas estão explorando um mercado tão importante para o veículo rádio.

São cinco as principais emissoras voltadas ao público jovem na cidade de São Paulo, todas no dial FM, dentro de um total de 66 emissoras AM e FM $(7,5 \%$ das emissoras): 89 FM A Rádio Rock (89,1 MHz), Disney (91,3 MHz), Metropolitana

2 De acordo com dados do Comitê Gestor de Internet, os domicílios com acesso à internet eram apenas $13 \%$ do total brasileiro em 2005, número que chegou para 43\% em 2013. A proporção de domicílios com banda larga, o que possibilita o uso mais recorrente de streaming de conteúdo de áudio e vídeo, passou de $22 \%$ a $66 \%$ do total (cf. BARBOSA, 2014). 
(98,5 MHz), Jovem Pan FM (100,9 MHz) e Rádio Mix (106,3 MHz). A soma de suas audiências correspondeu, em março de 2015, a uma média 13\% de participação na audiência total do rádio medida pelo Ibope $^{3}$ no horário entre $7 \mathrm{~h}$ e $19 \mathrm{~h}$, dias úteis. O elemento comum entre estas estações é uma programação predominantemente musical, com espaço limitado para programas de humor e informativos.

Para estudar o comportamento dessas emissoras, o artigo está dividido em duas partes. A primeira descreve e analisa as programações das cinco emissoras, para ilustrar as mudanças nas estratégias adotadas para dialogar com os ouvintes, como se compõe o público em termos de gosto musical e de que forma a rotatividade de audiência é explorada pelas emissoras. É central nessa análise conhecer o histórico da 89 FM, porque as razões que motivaram as mudanças em questão vão além das inovações técnicas: o gatilho foi, na verdade, o retorno ao dial de uma emissora conhecida por sua "liberdade criativa", que introduziu uma proposta de programação radiofônica inspirada nos velhos hábitos da audiência.

Estabelecida em 1985, a 89 FM segmentou-se no gênero musical rock, popular naquele momento pelo segmento new wave e pela forte expansão do mercado do rock nacional. Dos anos 1990 até meados dos anos 2000, a emissora foi aos poucos ampliando o leque de músicas que tocava em sua programação, se aproximando do pop-rock sem perder totalmente o modelo de segmentação que representava um público fiel. Uma estratégia comercial em 2005 transformou a emissora em uma "Contemporary Hit Radio" (CHR), sem segmentação musical definida, o que afastou esse público antigo e não foi eficaz em renovar a audiência. No final de 2012, prestes a ser arrendada para uma igreja, uma experiência via internet trouxe a emissora de volta, agregando tanto antigos ouvintes como novos.

A nova estratégia é a segmentação em subgêneros do rock e do pop-rock mundial, baseada principalmente em hits de meados dos anos 1980 até os dias atuais; a programação conta com forte presença de apresentadores e participação ao vivo do ouvinte, e uma comunicação digital bem integrada. No entanto, é importante ressaltar que tal modelo não é $100 \%$ voltado ao público jovem: ao mesmo tempo em que tenta dialogar com a audiência mais nova, a emissora tenta resgatar e manter o antigo ouvinte, o que muitas vezes resulta em programação anacrônica e contraditória, como veremos a seguir.

A segunda parte deste artigo mostra os resultados de uma enquete realizada via internet com pessoas entre 15 e 29 anos sobre as impressões e perspectivas que

3 O Ibope utiliza a metodologia Recall para medição de audiência de rádio. Os resultados são enviados mensalmente para as emissoras assinantes do serviço, e correspondem a uma média dos três últimos meses. Muitas emissoras não assinam essa pesquisa porque consideram a metodologia pouco confiável. No entanto, essa medição de audiência é uma das principais balizas para o mercado anunciante. 
possuem com relação às emissoras de rádio hoje. Como conclusão, desenvolvese uma reflexão sobre a importância do diálogo com a audiência e a formação do público jovem, como elemento da manutenção da viabilidade do veículo rádio em suas formas adaptadas ao ambiente digital.

\section{A rádio jovem paulistana: estratégias e diálogos}

\section{Música é (quase) tudo}

O que primeiro chama a atenção nas cinco estações selecionadas é a predominância de um playlist mínimo de lançamentos, isto é, o compartilhamento por todas as emissoras de uma seleção musical comum - próprio da estratégia de segmentação CHR. São canções segmentadas nos gêneros pop ou pop-rock trabalhadas internacionalmente por grandes gravadoras ${ }^{4}$, a maioria de artistas britânicos ou norte-americanos que, se não incluíram recentemente o Brasil na agenda de shows, têm planos para fazê-lo.

Essa primeira observação reforça a ideia de que a indústria radiofônica ainda é um braço importante de divulgação para a indústria fonográfica, conforme aponta Andrew Dubber ao comentar (e criticar) estratégias de seleção musical que nem sempre olham para o amplo espectro da segmentação: "(...) tocar (ou não tocar) certas peças musicais constrói audiências e reforça as poderosas relações entre o rádio e indústria musical, ao mesmo tempo em que impacta profundamente na cultura popular" (DUBBER, 2013, p. 78)5. Como o autor lembra, muitas emissoras encaram a reprodução de um conjunto limitado de músicas como "uma forma de construir audiências muito mais por meio de uma familiaridade reconfortante do que pelo engajamento ativo com os fãs" (DUBBER, 2013, p. 75) ${ }^{6}$.

A mesma percepção pode ser tomada de Warren, quando este autor afirma que "o rádio poderia ser muito melhor, entreter mais, ser menos previsível, e muito menos repetitivo se as pesquisas [sobre gostos] musicais fossem menos usadas, e os programadores das emissoras (e suas equipes) tivessem mais liberdade ao selecionar o material" (WARREN, 2013, p. 49)7. Isso afeta, inclusive, a estratégia

\footnotetext{
4 Para citar alguns nomes comuns a todas as emissoras: Imagine Dragons, Coldplay, Muse, The Lumineers e Pharrel, hoje grandes vendedores de música. relationships between radio and record industries, while it also impacts profoundly upon popular culture".

6 Do original: "a way of constructing audiences through a reassuring familiarity rather than through an engagement with active fandom".
}

7 Do original: "radio could be a lot better, more entertaining, less predictable, and far less repetitive if music research were used less and radio programmers (and staff) had more freedom to select material". 
de lançamentos de músicas: ao mesmo tempo em que promove conceitos de "lançamento" e "novidade", a escolha das canções que entram no playlist é limitada a um pequeno conjunto que se assemelha àquilo que já é regularmente tocado. "Como resultado, é muito difícil para as gravadoras inserir novos artistas no mundo do rádio comercial, e muito mais difícil para novos subgêneros, para trabalhos mais exploratórios" (DUBBER, 2013, p. 87)8. Fica patente, nessa estratégia publicitária, a concorrência que o veículo tenta empreender contra as possibilidades de descoberta de música por outros meios, ao mesmo tempo em que limita a oferta a um conjunto de produções, realizando no setor musical algo próximo à ideia de agenda setting do jornalismo.

A segunda nota deve-se ao mix de música que as emissoras propõem em meio aos lançamentos, o que torna evidente como elas se diferenciam em suas essências. A 89 FM, por exemplo, não toca qualquer música considerada pop, como Lady Gaga ou One Direction, que não tenha uma raiz no pop-rock. Ao mesmo tempo, opera uma seleção de hits pop-rock especialmente recortada nos anos 1990 e 2000, com uma ou outra canção de décadas anteriores. O resultado disso é uma playlist recheada de hits mais antigos, que dialoga com uma parcela de público mais velha, e de hits do pop mundial que transitam próximo ao rock n'roll, mas que nunca seriam definidas como rock pelos ouvintes mais puristas, como Peter Bjorn and John. Assim, alguns lançamentos naturalmente incorporados à sua programação passaram a ser replicados pelas demais emissoras.

A Disney, por outro lado, é a mais diversificada das estações, pois muitas vezes foge completamente do recorte pop e insere canções antigas e gêneros nacionais, como sertanejo, axé e MPB, no que podemos considerar a playlist mais eclética de todas as emissoras. A Mix e a Metropolitana, por outro lado, se mantêm muito mais fiéis ao pop e ao pop-rock, abrindo exceções para o Funk brasileiro que hoje domina as rádios mais populares do dial. Essas duas emissoras assemelham suas programações musicais à estratégia de playlist parecida com o conceito Top 40, bem como a Jovem Pan.

É importante ressaltar a predominância de músicas estrangeiras nas programações, com pouco espaço para os músicos e grupos nacionais. Nesse ponto, novamente o modelo da 89 FM se destaca, pois desde seu retorno usa como estratégia de propaganda o lançamento de novos grupos musicais brasileiros.

8 Do original: "As a result, it is very difficult for record companies to 'to break new artists in the world of commercial radio, and even more difficult for new subgenres, for more exploratory works".

9 Enquanto CHR refere-se a uma programação baseada principalmente em lançamentos, mas com midbacks e flashbacks para compor a programação mais ampla, Top 40 é aquela programação em que apenas as 40 mais tocadas rodam o dia todo, com pouca alternância com outras músicas. Muitas vezes, os termos CHR e Top 40 são usados como sinônimos. Escolhemos manter os dois termos porque essas três emissoras (Mix, Jovem Pan e Metropolitana) mantêm um playlist muito mais restrito e com alta taxa de repetição de músicas durante um dia de programação. 
Assim, ao mesmo tempo em que esses grupos representam o "novo" na emissora, passaram a ser conhecidos pelo público e a estar presentes em outras estações. Essa tática, no entanto, ainda é bastante incipiente para ser possível afirmar que há uma revalorização da música nacional empreendida por essas empresas, deixando aberto um espaço que pode ser melhor ocupado.

\section{A volta do disc jockey}

Pode parecer estranho anunciar a "volta" de um tipo de profissional que, a rigor, nunca deixou de estar presente nas emissoras de rádio. No entanto, o título desta seção não poderia ser mais bem apropriado para representar a sensação despertada pelo formato de programação que algumas emissoras voltaram a implementar, com ampla participação do locutor em meio à música. O contexto que explica tal observação parte de uma observação histórica, que remete aos anos 1970 e à implantação do dial FM no Brasil.

Como estratégia de um plano de revitalização do rádio para atender necessidades da ditadura militar, o governo brasileiro incentivou a implantação das emissoras FM no território brasileiro nos anos 1970 (BIANCO, 1999, p. 190191). Em um primeiro momento, essas rádios visaram principalmente o público adulto qualificado, isto é, com maior poder aquisitivo, e emitiam especialmente uma programação musical - aproveitando a sensível melhor qualidade de áudio do dial. No final da mesma década, começam a proliferar emissoras de rádio voltadas ao público jovem, cuja programação era comandada por um tipo de apresentador inspirado nos disc jockeys norte-americanos (FERRARETTO, 2001, p. 51-53).

Apesar da locução acelerada e da predominância quase total das músicas, essa figura se materializou no imaginário do ouvinte como o grande conhecedor do mundo musical na década seguinte - a pessoa que trazia os sucessos internacionais para o cotidiano brasileiro. Para resumir, toda a estratégia da programação FM foi baseada nesse modelo de locutor, que por vezes interagia e brincava com seu público, mas que principalmente era o comandante de grandes playlists musicais. Nos anos 1990, especialmente por conta da formação de redes de rádio que se distribuem via satélite pelo país, esse locutor foi perdendo espaço: isto é, falando menos, muitas vezes se limitando a apenas anunciar músicas e horas, especialmente nas emissoras voltadas para o público jovem (GAMBARO; VICENTE, 2013, p. 55).

A "novidade" que algumas emissoras estão trazendo de volta é a personalidade do locutor. Especialmente na 89 FM e na Disney, é perceptível a presença mais marcante de um apresentador que conhece a música, que comenta e que conversa com o ouvinte, de forma moderada. Claro, diferentemente dos disc jockeys que 
caracterizaram os primeiros anos da FM, toda a negociação a respeito do lançamento de músicas e artistas, hoje, passa primordialmente pela emissora e não mais pelo locutor. No entanto, é a forma de condução dos programas que parece estar sendo resgatada do passado. Como parte da retomada do diálogo com o ouvinte, estão: a distribuição de prêmios; a opinião dos locutores sobre as músicas tocadas, muitas vezes, apoiada nas estratégias da indústria musical; e o comentário sobre fatos do cotidiano, algumas vezes carregado com os preconceitos do comunicador. Faltam, no entanto, o embasamento histórico e o profundo conhecimento artístico que o locutor trazia na primeira fase do FM.

É importante destacar que a figura do disc jockey é fundamental na criação de laços de identidade com a audiência jovem (WARREN, 2013). O mesmo vale para a figura do apresentador que cultiva sua personalidade com a audiência, uma característica que, segundo Ruddin (2011, p. 63), é o principal diferencial do rádio.

Infelizmente, esse procedimento está distante de ser adotado de forma homogênea pelas emissoras. O destaque mais negativo fica para Metropolitana e Mix, emissoras em que o locutor apenas grita o nome da música e, vez ou outra, a hora. Na Jovem Pan, quando não há programas noticiosos ou de entrevistas, predominam longos playlists musicais sem interrupção do locutor. A vantagem nessa programação é o barateamento de custos, mas o preço que se paga é o menor apelo publicitário, em função de uma audiência muito mais rotativa e dispersa.

\section{Humor e talk-show}

Em uma linha semelhante à renovação do apresentador com personalidade, algumas emissoras de rádio têm investido em programas animados, apresentados por muitas vezes por um conjunto de pessoas - além do host principal. Normalmente, esses programas são morning shows, mas em algumas emissoras o principal momento é a hora do almoço e, para outras, o começo da noite.

O caso mais emblemático é o da rede Jovem Pan, que no primeiro horário matinal replica no dial FM o jornal hard news de sua filial em AM, voltado para o público adulto. Em seguida, na transição para o público mais jovem e adolescente que caracteriza sua programação, entra no ar o "JP Morning Show", uma variedade de infotainment que privilegia o bate-papo com entrevistados e o soft news. Ao meio dia, começa um dos programas mais antigos do rádio FM ainda em atividade - e um dos mais ouvidos nessa faixa horária: o "Pânico". Trata-se de um humorístico com a participação de vários locutores que interpretam personagens, recebem ligações de ouvintes e conduzem entrevistas bem-humoradas com diferentes personalidades. Às seis da tarde, novamente forma-se rede com a 
Jovem Pan AM para um programa em que impera o comentário político, mais uma vez fugindo do público assumido pela emissora em busca de ampliar, na FM, a audiência da emissora AM.

Essa estratégia de segmento de público por horário aproveita melhor a curva de audiência dos diferentes targets. Como analisado por FERRARETTO (2014, p. 56), enquanto a audiência do público adulto tem a maior curva no meio da manhã, a audiência do público jovem cresce durante a manhã e tem picos no começo e no final da tarde, concentrados em programas de humor similares ao "Pânico". O hábito de ouvir certo programa mantém a fidelidade do ouvinte a um determinado horário (algo que começa a ser rompido pelo timeshifiting da programação on demand), mas, ao mesmo tempo, dificulta a fidelização à marca que representa a emissora de rádio. Olhar apenas as curvas de audiência para oferecer programas diferentes inviabiliza, por exemplo, o engajamento do público em outros horários fora dessa faixa principal. Como indica Warren, é um grande erro de programação achar que a música é o formato e ignorar a informação e a personalidade radiofônica, tanto quanto "ignorar música e informação quando pesquisas indicam que as personalidades radiofônicas podem ser consideradas pela audiência o principal elemento do formato" (WARREN, 2013, p. 39) ${ }^{10}$.

As demais emissoras são menos radicais nessa escolha que a Jovem Pan. Quando optam pelos morning shows, limitam-se ao anúncio rápido de notícias, muitas vezes soft news, e o tom de humor e descontração toma conta dos programas - caso principalmente da Disney. Na 89 FM, das $10 \mathrm{~h}$ às $13 \mathrm{~h}$ predominam programas com apresentadores que fazem piadas e abrem participação para o ouvinte ao vivo. Os programas predominantemente falados, no entanto, estão no final da tarde. Mix, Metropolitana e 89 FM apresentam programas em que os apresentadores mesclam música e bate-papo com o ouvinte. No caso da Mix e da Metropolitana, fazem sucesso há anos programas em que os apresentadores fazem trotes telefônicos.

O que se compreende a partir dessa tendência é que o público jovem usa a emissora muito mais do que como playlist musical. Desde o seu retorno, a 89 FM vem aos poucos ampliando os programas ancorados por apresentadores cuja principal característica é o humor - algo que, de certa forma, sempre marcou o horário do final da tarde em diferentes emissoras. Com exceção das estratégias que miram em um público diversificado - como a da Jovem Pan -, esses programas mesclam de modo mais homogêneo música e fala e dão continuidade à linguagem geral da emissora, reforçando traços de identidade com o público.

10 Do original: "ignoring music and information when research shows personalities may be considered by audience to be the strongest element in the format". 
Em um nível de aposta mais elevado, é possível afirmar que a proposta do humor acostuma novamente o ouvinte a uma programação predominantemente falada. O exemplo mais emblemático disso é o programa de bate-papo e entrevistas "Quem não faz, toma", da 89 FM - que editou, por diversas vezes nos últimos dois anos, seriados radiofônicos de curta duração. Esquetes humorísticas com personagens fixos são comuns em várias emissoras, como Mix e Metropolitana, mas a ideia de um programa seriado que utiliza a totalidade de recursos da linguagem sonora traz a possibilidade de retorno de um tipo de programa há muito tempo ausente das principais emissoras brasileiras: o seriado radiofônico.

\section{O ouvinte está ao vivo}

O resultado direto da estratégia de dar mais voz aos locutores se reflete também em maior participação do ouvinte, principalmente por telefone, mas também por meio de mensagens de voz enviadas via aplicativos de celular, como Whatsapp ou Viber, mensagens no Facebook ou Twitter e, em menor escala, e-mails. Quando ao vivo, o tempo de voz do ouvinte é limitado, mas sua simples presença reforça o laço de identificação que une o grupo de ouvintes que seguem a emissora (GAMBARO; VICENTE, 2013, p. 56-57).

Embora essa estratégia sempre tenha sido uma marca das emissoras populares ${ }^{11}$, seria praticamente inimaginável cerca de 10 a 15 anos atrás, quando as emissoras jovens viviam basicamente de playlists musicais. Poucos eram os momentos em que o ouvinte teria condições de se imaginar participando da programação. Essa ação parece dar certo pois também resgata a distribuição de brindes: em uma estratégia de fidelização da marca, o ouvinte garante um objeto que leva ao cotidiano e pode, assim, ampliar a reputação da emissora entre seus amigos, atuando como um multiplicador publicitário para a empresa. Segundo Jenkins,

Os profissionais de marketing procuram moldar a reputação das marcas não através de uma transação individual, mas através da soma total de interações com o cliente - um processo contínuo que cada vez mais ocorre numa série de diferentes 'pontos de contato' midiáticos (...) Novos modelos de marketing procuram expandir os investimentos emocionais, sociais e intelectuais do consumidor, com o intuito de moldar os padrões de consumo (JENKINS, 2008, p. 96).

11 Emissoras do segmento popular são, no Brasil, voltadas principalmente para música nacional: samba, sertanejo, pagode e funk brasileiro. A programação é, geralmente, marcada pela participação do ouvinte durante a programação para ganhar prêmios ou contar histórias pessoais. Algumas emissoras populares em FM mantêm programas inteiros sem música, apenas com a participação do ouvinte. 
O ponto negativo está na necessidade constante de produzir outros materiais que fogem da finalidade primária da emissora: o conteúdo. De certa maneira, o que se constata efetivamente é uma preocupação reduzida com a qualidade da informação prestada - conforme já apontado - e a garantia da audiência por meio de ações que são perenes e banais, apesar de mais custosas.

\section{A web virou menu}

Boa parte da estratégia de participação do ouvinte passa pela internet ou pelos serviços oferecidos pela rede. As páginas das cinco emissoras estão configuradas para oferecer conteúdos que extrapolam o que normalmente se conheceria como rádio. Essas ferramentas são:

(...) navegação, links hipertextuais-hipermediais e interatividade, assim como outras possibilidades. Surge a ciberrádio propriamente dita, que outorga outro papel à audiência. É possível acessar e navegar por toda a programação ou apenas por fragmentos da programação e do programa. Algumas partes ficam separadas por gêneros, como comentários, entrevistas, reportagens, crônicas. A isto, soma-se a capacidade de interatividade ou links que se deseja oferecer. Cada fragmento adquire autonomia (HERREROS, 2007, p. 35). ${ }^{12}$

Fotos e vídeos viraram praxe e fazem parte da estratégia do rádio na rede, mas os principais objetos acabam sendo, no entanto, notícias segmentadas no recorte musical e no gosto da audiência e a participação de promoções.

Entretanto, é importante reafirmar que os usos dados pelas emissoras aos seus websites ainda estão longe do ideal. Jovem Pan FM marca alguma diferença, ao transmitir seus dois principais programas (o "JP Morning Show" e o "Pânico") ao vivo, com uma edição de vídeo semelhante a um programa de TV, e depois disponibiliza trechos on demand. A ideia por trás disso é, além de possibilitar que o ouvinte recupere parte da programação perdida, aproximar o usuário da internet de uma programação que tem apelo inclusive pela imagem. Com relação às demais emissoras, no entanto, o conteúdo on demand é normalmente muito pobre, baseado em "notícias frias", quando deveria replicar, de forma mais consistente, o conteúdo que vai ao ar. Isso atenderia melhor ao fenômeno do timeshifting digital que, segundo Dubber, implica em que "a audiência se torna mais seletiva,

12 Do original: "(...) navegación, enlaces hipertextuales-hipermediales e interactividad, así como otras posibilidades. Surge la ciberradio propiamente dicha, la cual otorga otro papel a la audiencia. Puede efectuarse el aceso y navegación por toda la programación o sólo por fragmentos de la programación y programas. Hay algunas partes que quedan separadas incluso por géneros como los comentarios, entrevistas, reportajes, crónicas. A esto se añade la capacidad de interactividad o enlaces que quieran ofrecerse. Cada fragmento adquiere autonomía". 
deliberada (...) os ouvintes podem selecionar [o que ouvir] a partir de um vasto menu e ativamente escolher o que é de maior interesse para eles" (DUBBER, 2013, p. 52) ${ }^{13}$.

Talvez mais eficaz do que um website para o público almejado seja um perfil em rede social, por meio do qual a estação pode compartilhar conteúdos diversos - inclusive memes engraçados que, muitas vezes, se tornam virais entre os ouvintes da emissora. Algumas emissoras concentram promoções diárias aquelas que distribuem brindes mais comuns, como camisetas e ingressos para festas - diretamente no Facebook, ao invés do website. Apesar de reforçar a marca da estação, esses procedimentos nem sempre criam um verdadeiro engajamento do ouvinte, para transformá-lo em um verdadeiro fã da emissora. Assim, com exceção às promoções, muitas vezes o ouvinte/usuário não encontra verdadeiros motivos para retornar à página da estação de rádio.

\section{A opinião de quem ouve}

Para compreender melhor como essas mudanças que as emissoras jovens vêm implementando impactam a audiência, foi feita uma pesquisa via internet com pessoas dentro da faixa etária principal - 15 a 30 anos de idade, no mês de abril de 2015. Responderam ao questionário online 174 pessoas, que expuseram suas opiniões em relação à programação radiofônica atual. Apesar do formato da pesquisa não permitir uma formulação estatística dos resultados - devido ao tamanho da amostra frente ao universo total pesquisado -, essa investigação permite obter alguma informação sobre as preferências e expectativas da audiência.

Do total de entrevistados, 70\% afirmaram ouvir rádio pelo menos uma vez por semana, número semelhante ao total apurado pelos institutos de pesquisa como penetração do meio. Mais da metade desses entrevistados afirmam ouvir rádio todos os dias ou praticamente todos os dias. No entanto, enquanto dados de mercado da audiência do rádio apontam a faixa da manhã, especialmente até o meio-dia, como o principal horário de audiência do meio, os respondentes se distribuíram de forma quase homogênea entre as $9 \mathrm{~h}$ da manhã até o final da tarde, com leve predominância para a faixa entre $14 \mathrm{~h}$ e $17 \mathrm{~h}$.

\section{A escolha das emissoras}

Quando solicitados a classificá-las por preferência, a Jovem Pan foi indicada como muito ouvida por $45 \%$ dos entrevistados, seguida pela Mix (33\%) e pela 89 FM (31\%). Essa informação aponta para duas características interessantes do

13 Do original: "(...) is that listening takes on more of a selective, deliberate quality (...) listeners may select from a vast menu and actively choose what is of great interest to them". 
movimento da audiência. Primeiro, é preciso considerar que o principal horário de audição para a maior parte dos ouvintes que preferem a Jovem Pan é a hora do almoço (quando "Pânico" está no ar) e a faixa entre 17h-20h, que engloba primeiro um playlist musical, seguido do programa jornalístico replicado da AM. Mesmo que a audiência mude da Jovem Pan para outra emissora, em ambos os horários estão no ar programas com foco em informação, humor ou bate-papo, como apontado anteriormente.

Com segurança, podemos afirmar que prevalece a escolha pela predominância da música na programação, mas o fato de programas com foco em jornalismo e entrevistas estarem nesses mesmos horários desperta atenção ao estilo de programação. Para compreender melhor esse impacto, é preciso levar em conta o segundo dado interessante desse levantamento: entre os que preferem a Jovem Pan, 57\% também têm como emissora preferida a Mix FM (no momento da pesquisa, a primeira colocada entre as emissoras jovens, segundo dados do Ibope). Essa transferência de ouvintes se repete quando observamos as preferências entre Mix e Metropolitana, sendo que mais da metade dos respondentes que escolheram uma delas como preferida também selecionou a outra.

É plausível sugerir que essa facilidade de migração de uma emissora a outra deve-se à falta de uma personalidade que vincule o ouvinte, uma vez que a seleção musical das três emissoras, especialmente durante as longas playlists sem intervalos comerciais, é praticamente idêntica, como destacado acima. Esta discussão ganha conotação diferente quando comparamos os ouvintes que selecionaram a $89 \mathrm{FM}$ como preferida: cerca de $50 \%$ deles também afirmou escutar com frequência a Jovem Pan, e a preferência de horário entre os ouvintes da 89 FM também é a hora do almoço e o final da tarde, quando estão no ar na Rádio Rock programas que mesclam música e fala. O caminho contrário, no entanto, não é verdadeiro, porque o número de ouvintes em comum entre essas duas emissoras representa apenas $35 \%$ dos ouvintes da Jovem Pan. A migração dos ouvintes da 89 FM não se repete com as demais emissoras. Em resumo, existe uma parcela significativa de público que se mantém fiel à emissora, muitas vezes por conta dos apresentadores e da marca que eles representam.

\section{Como e onde ouvir rádio}

Quando perguntados em que local costumam ouvir rádio com mais frequência, $41 \%$ afirmaram que é no carro e outros 30\% no celular. Em outras palavras, $71 \%$ ouvem rádio com mais frequência quando estão em deslocamento, o que o coloca como um "acompanhamento" de atividades que requerem atenção ${ }^{14}$.

14 Não obstante, quando questionados sobre todos os meios que usam para ouvir rádio, 56\% afirmaram usar o carro e $51 \%$ o celular, o que indica que o número de pessoas que ouvem o rádio em trânsito é maior. 
No universo pesquisado, 55\% dos respondentes informaram não acessar o site das emissoras de rádio que estão no dial. Entre os que acessam, as principais atividades são: 1) ouvir a rádio online; 2) ouvir outras músicas além da programação; e 3) acessar promoções. O fato de menos da metade dos ouvintes acessarem a web para ouvir a programação da rádio indica muito mais a falta de hábito desse tipo de consumo do que concorrência online: $73 \%$ dos respondentes afirmam não buscar webrádios na internet, e apenas $48 \%$ assinam serviços de streaming de músicas. Parte da explicação tem a ver com a percepção sobre o modo como as emissoras usam a $w e b$ : apenas $17 \%$ acham que as estações fazem um bom uso das ferramentas online, enquanto $59 \%$ consideram essencial que a emissora tenha um website com conteúdo variado e $63 \%$ demandam que as emissoras mantenham formas de contato via web.

\section{Música vs. Locutor}

Como apontado anteriormente, há o predomínio da música na vontade do ouvinte, apesar de a presença humana ser destacada pela maioria dos entrevistados. Isso se deve, principalmente, ao fato de que a rádio é um meio importante na descoberta de música para a maior parte dos entrevistados, apesar da predominância da internet: 36\% afirmam conhecer música principalmente pelas estações de rádio, enquanto $39 \%$ afirmam que o principal meio é procurando na $w^{2} b^{15}$.

Dessa forma, o rádio desempenha um papel significativo para a indústria musical mais robusta, capaz de bancar altos custos de lançamento e a manutenção de artistas. Apesar disso, é um tanto contraditória a percepção sobre como as emissoras de rádio apresentam músicas: apenas $48 \%$ concordam ao menos parcialmente com a afirmação de que as emissoras tocam mais músicas que os agradam do que não agradam; apenas $47 \%$ acham que é suficiente o número de novidades incluídas na programação; e $80 \%$ dos respondentes sinalizaram o excesso de repetição de uma mesma canção.

Sobre os locutores, a percepção que os ouvintes têm hoje é variada: 53\% concordam ao menos parcialmente com a afirmação de que os locutores são compatíveis com a faixa etária jovem e $27 \%$ do público consultado é indiferente a essa afirmação. Ao mesmo tempo, 44\% concordam ao menos parcialmente com a afirmação de que, hoje, os locutores falam demais e isso atrapalha a programação, contra $43 \%$ que discordam ao menos parcialmente, e $13 \%$ que são indiferentes ao papel do locutor hoje. Esse empate traduz melhor a percepção de que a emissora

15 Ao sobrepor os dados, $90 \%$ afirma procurar música nova na internet, $79 \%$ ouve no rádio e $77 \%$ em trilhas musicais de filmes e programas de TV. 
deve introduzir a presença do locutor como diferencial de sua programação, ao mesmo tempo em que deve levar em conta que essa estratégia pode soar estranha para o ouvinte desacostumado com a presença da voz no ar. Os dados seguintes ilustram melhor esta percepção.

\section{A emissora ideal}

Para fechar esta seção, foram feitas três perguntas sobre como os respondentes imaginam uma emissora ideal. Sobre o perfil musical, 51\% acreditam que as rádios devem mesclar diferentes estilos musicais, enquanto $37 \%$ acham importante a variação de diferentes vertentes em um mesmo estilo musical. Quando perguntamos sobre a presença dos locutores na programação, 57\% dos ouvintes acreditam que as emissoras devem priorizar a programação musical, mas podem ter programas jornalísticos, esportivos e de humor, enquanto $26 \%$ acreditam que as rádios devem balancear música e fala. Especificamente sobre o papel do locutor, $43 \%$ preferem que ele fale pouco, mas traga informações interessantes sobre os artistas e as músicas tocadas. Outros $23 \%$ afirmam que o locutor deve falar o suficiente para imprimir sua marca pessoal. Ou seja, $66 \%$ dos entrevistados preferem um locutor que fale do que uma rádio que seja somente playlist musical, dado que ganha força quando $64 \%$ dos respondentes afirmam ser pelo menos interessante que o ouvinte tenha a possibilidade de entrar em contato com o locutor via internet.

\section{Conclusão}

Ao observar as estratégias das emissoras de rádio voltadas ao público jovem, hoje, percebemos como o impacto do entorno digital vem reconfigurando as ações das emissoras ao criar o diálogo com o seu ouvinte. Em primeiro lugar, destaca-se o fato de que, apesar dos avanços tecnológicos que vêm sendo incorporados ao "fazer rádio", foi necessário olhar para trás para resgatar algumas características centrais do meio, enraizadas historicamente.

Durante um longo tempo, o veículo foi tratado como um meio secundário e de apoio a outra indústria, a musical. Os efeitos repercutem até hoje: se a programação estava disponível apenas para a descoberta de músicas, os players de MP3 e os serviços de streaming vieram para destronar o rádio de sua função simples, porém quase exclusiva. Objetivamente, o veículo perdeu força entre os mais jovens naquilo que foi economicamente determinado como sua função central. Não faltam críticas a esse apelo dado, ainda hoje, à forma musical do rádio. Warren é enfático ao afirmar que "o romance entre o rádio e a indústria fonográfica fez os pesquisadores acreditarem que as únicas músicas que eles deveriam pesquisar são 
os hits" (WARREN, 2013, p. 74) ${ }^{16}$. De certa forma, o papel do rádio sai duplamente empobrecido: em sua função como caminho para o conhecimento de novos artistas e suas produções e em sua função educativa de apresentar uma diversidade maior ao público ouvinte - especialmente o público jovem, em formação. Além disso, playlists semelhantes promovem aos ouvintes a facilidade de "trocar de canal" a qualquer momento, sem ouvir o elemento mais importante da manutenção da emissora de rádio: o anunciante.

O resgate à presença da voz do locutor, algo que é sugerido como necessário a partir dos dados levantados por meio das entrevistas, mostra força como a estratégia da vez. No entanto, como observamos, esse resgate não deve simplesmente se apoiar no locutor como única possibilidade, haja vista que o rádio acostumou o público, durante muito tempo, a uma programação praticamente sem voz. Uma anotação simplista poderia afirmar que o tocador de MP3 não traz a personalidade e a companhia que o locutor propõe em uma programação de rádio. Por mais correta que seja essa afirmação, a questão é mais profunda. O rádio é um meio secundário, uma companhia, segundo Warren (2013) - isto é, o ouvinte realiza outras ações e não está exatamente prestando atenção na programação. Ferraretto analisa esse papel e destaca que a produção radiofônica deve levar em consideração diferentes condições de recepção, porque o ouvinte dedica, durante o consumo do programa, diferentes níveis de atenção (Ferraretto, 2014, p. 36-38).

Colocar um locutor como voz de fundo apenas reforça essa relação com o rádio, em que os momentos de concentração são escassos. O que se percebe a partir dos dados expostos neste artigo vai além, ao propor que a relação com o ouvinte é a da criação de uma marca indelével que o identifica com a emissora. Basta olhar para o dado sobre compartilhamento de ouvintes entre diferentes emissoras para se ter o exemplo sobre a necessidade de criação de vínculos - o que não ocorre por meio de uma voz que, vez por outra, chama o ouvinte para uma conversa de poucos segundos.

Apesar de essa solução ser plausível no cenário atual, os impasses que se colocam são muitos. Primeiro, vem a questão da dosagem da presença da voz falada entre as músicas, uma vez que o ouvinte atual tem como referência uma playlist musical interminável, com horas de programação sem qualquer informação. Segundo, deve-se levar em conta a qualidade da informação que se deve prestar e do perfil do profissional que vai dar essa informação: sua figura deve se assemelhar ao especialista, o que provavelmente encarece o custo de produção radiofônico.

16 Do original: "the love affair between the radio and the record industries has made music researchers believe that the only music they ever need to research are the hits". 
Em certa medida, as emissoras (e alguns locutores que ocupam a cadeira à frente do microfone) esqueceram a responsabilidade que têm na comunicação de ideias. Em resumo, deve-se fazer presente, nesse cenário, o princípio econômico de essencialidade (apenas o necessário entra) e a funcionalidade (deve servir para algo maior que o simples momento de interação).

Um terceiro ponto exige rever a produção para o ambiente digital, com melhor integração entre as plataformas e a oferta de um cenário amplo de consumo restrito à marca da emissora. Se considerarmos possíveis mudanças na forma de consumo do rádio, as emissoras devem entregar ao ouvinte conteúdo alternativo de qualidade, que reforce sua linha com o ouvinte. Da mesma forma, a programação da emissora deve ser distribuída de um modo mais acessível ao ouvinte/usuário, que não se prende apenas ao tempo da emissão (DUBBER, 2013, p. 52-53). Assim, ao se produzir programas para programação contínua, devese levar em conta que esse mesmo conteúdo pode ser dividido e disponibilizado online (o que é impossível para emissoras que valorizam apenas a playlist).

Não obstante os problemas que podem se desenhar a partir das estratégias adotadas, é muito importante que as emissoras criem vínculo com seus ouvintes, especialmente os adolescentes e jovens adultos. Trata-se, principalmente, de demonstrar a relevância do rádio no atual cenário de multiplicidade de oferta de conteúdo, para promover a criação e manutenção de um público que continuará a consumir o veículo junto com todas as outras mídias que proliferam nas versões digitais, mesmo que o futuro do rádio seja basear-se unicamente na web. 


\section{Referências}

BARBOSA, A. F. (Coord.). Pesquisa sobre o uso das tecnologias da informação e comunicação no Brasil: TIC domicílios e empresas 2013. São Paulo: Comitê Gestor de Internet no Brasil, 2014.

BIANCO, N. R. D. "Tendências da programação radiofônica nos anos 90 sob o impacto das inovações tecnológicas". In: DEL BIANCO, N. R.; MOREIRA, S. V. (orgs.). Rádio no Brasil: Tendências e Perspectivas. Rio de Janeiro: EdUERJ; Brasília: UnB, 1999, p. 185-204.

DUBBER, A. Radio in the digital age. Cambridge, UK: Polity Press, 2013.

FERRARETTO, L. A. "Tendências da programação radiofônica: as emissoras em amplitude modulada". In: MOREIRA, S. V.; BIANCO, N. R. (Orgs.). Desafios do rádio no século XXI. São Paulo: Intercom; Rio de Janeiro: UERJ, 2001, p. 47-61.

FERRARETTO, L. A. Rádio: teoria e prática. São Paulo: Summus, 2014.

GAMBARO, D.; VICENTE, E. "A (re)valorização do locutor na internet: estratégias do rádio em um cenário de reconfiguração digital". Revista de Radiodifusão. v.7, n. 8 , set. 2013, p. 52-60.

GRUPO de Mídia SP. Mídia Dados Brasil 2015. São Paulo: Autor, 2015.

HERREROS, M. C. La radio en internet: de lo ciberradio a las redes sociales y la radio móvil. Buenos Aires: La Crujía, 2007.

JENKINS, H. Cultura da convergência. São Paulo: Aleph, 2008.

RUDIN, R. Broadcasting in the $21^{\text {st }}$ Century. London, UK: Palgrave Macmillan, 2011.

WARREN, S. Radio: the Book (kindle edition). London, UK, New York, USA: Focal Press, 2013, retrieved from Amazon.com.

submetido em: 26 out. 2015 | aprovado em: 04 dez. 2015 